\title{
The Super Cyclonic Storm Amphan Inflicts Massive Damage to Coastal Aquaculture in Bangladesh
}

\author{
Shoaibe Hossain Talukder Shefat ${ }^{1,2 *}$ \\ ${ }^{1}$ Resilient Small-Scale Fisheries Program, WorldFish Bangladesh and South Asia, \\ Banani, Dhaka, Bangladesh \\ ${ }^{2}$ Department of Fisheries Management, Bangabandhu Sheikh Mujibur Rahman \\ Agricultural University, Gazipur, Bangladesh
}

*Corresponding Author: Shoaibe Hossain Talukder Shefat, Resilient Small-Scale Fisheries Program, WorldFish Bangladesh and South Asia, Dhaka and Department of Fisheries Management, Bangabandhu Sheikh Mujibur Rahman Agricultural University, Gazipur, Bangladesh.

The monstrous cyclone Amphan, formed in the Bay of Bengal was the strongest tropical cyclone affecting the Ganges delta after Sidr in 2007 that caused severe damage in India and Bangladesh in May 2020. It was also the first tropical cyclone in the North Indian Ocean in 2020. Originating from a low-pressure area in Colombo, Sri Lanka on 13 May 2020, Amphan reached its maximum intensity on 18 May that sustained for 4-minutes with a wind speed of 240 - $260 \mathrm{~km} / \mathrm{h}$ (150 - $160 \mathrm{mph}$ ), and a minimum central barometric pressure (925 mbar) (Figure 1). However, the intensity gradually weakened by continuous and combined dry air and wind shear effects and reached a residuum level on 21 May. During this period, Amphan caused severe destruction of more than US $\$ 13$ billion in India and Bangladesh.

More than one million populations in nine coastal districts in Khulna and Barishal divisions were severely affected by the cyclone Amphan (Figure 2) causing an estimated economic loss of US\$130 million, destroying standing crops and washing away fishes from most of the shrimp enclosures and water bodies in the coastal regions. Only the coastal fish farmers (shrimp, finfish and crab farmers) of these two divisions faced the worst fate of loss of at least US\$25.5 million due to Amphan.

The coastal low-lying areas went under 3 - 4 feet water and around 3,000 shrimp and crab farms were severely destroyed and the freshwater fish ponds in the Sundarbans were inundated by
Received: May 26, 2020

Published: May 31, 2020

(C) All rights are reserved by Shoaibe

Hossain Talukder Shefat.

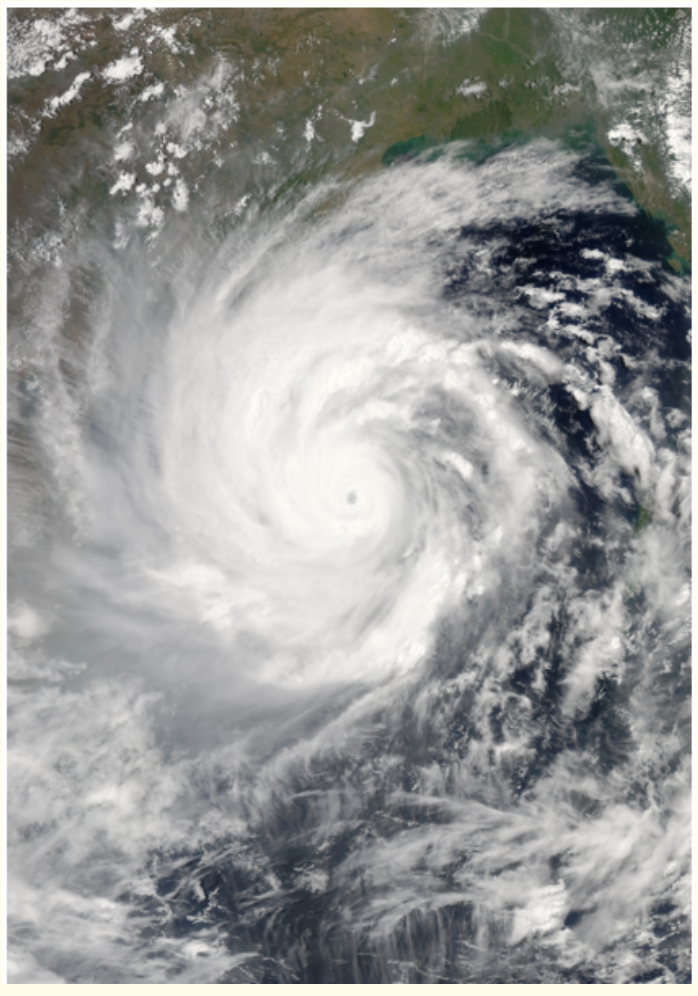

Figure 1: Super cyclonic storm Amphan at near peak intensity over the Bay of Bengal on May 18. 


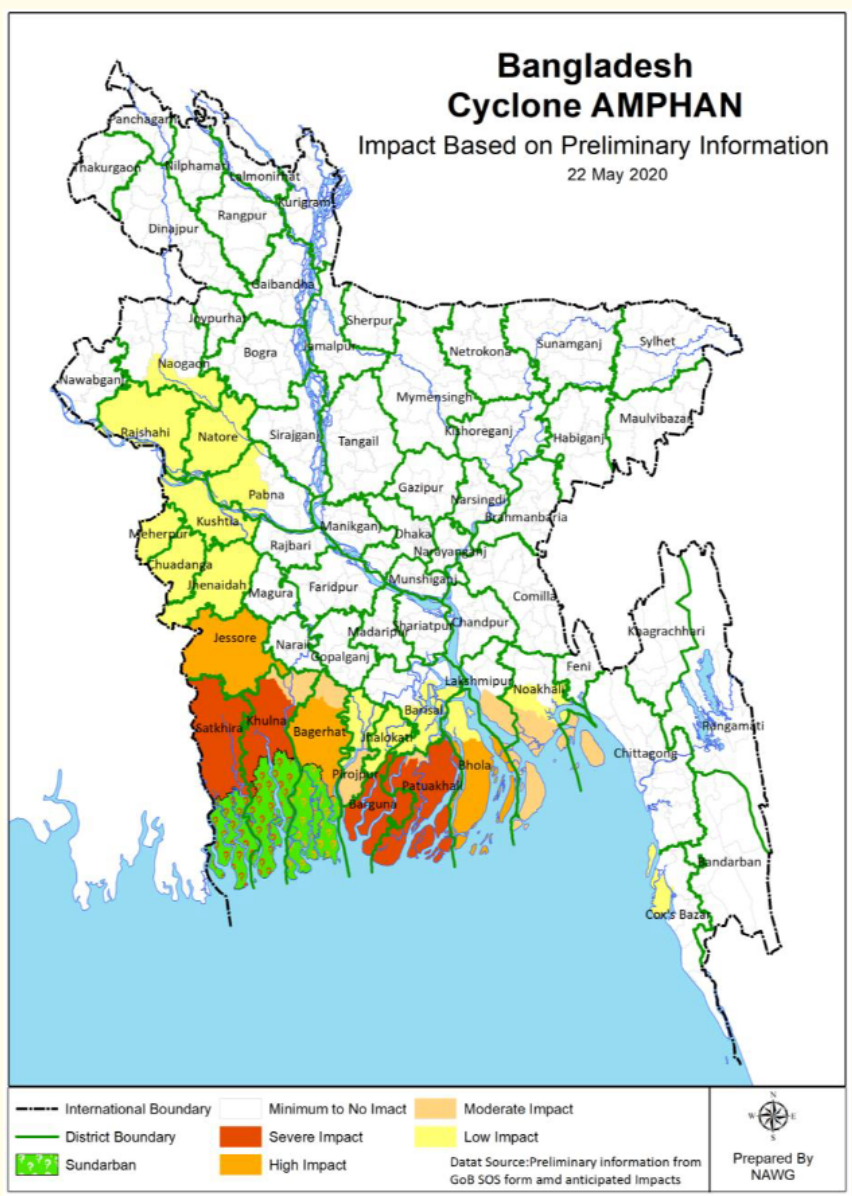

Figure 2: Preliminary assessment of damage inflicted by the tropical cyclone Amphan in Bangladesh.

saltwater. Another source claimed that more than 10,000 shrimp enclosures were washed away in Satkhira, Bagerhat, and Khulna. The post-larvae of shrimps stocked by the farmers in enclosures were also partially washed away due to the damage of embankments in Sathkhira.

The Deputy Commissioner of Satkhira, SM Mostafa Kamal said, "At least 12,257 fish enclosures and ponds (13,477 hectares) in the district have been flooded and result in washout of 1,677 tons of whitefish and 2,531 tons of shrimp, worth over approximately BDT 176 crore". According to Bagerhat District Fisheries Office, "At least 4,635 shrimp fishing grounds in the district were washed away by the storm which will severely affect the fish farmers of the district.
19,000 fish farms, fences and ponds have been damaged in six districts of Barishal division, Department of Fisheries claimed. According to the Pirojpur district fisheries office, around seven thousand fish farms were washed away only in Pirojpur district due to Amphan flooding. Cyclone Amphan has damaged many houses and fish ponds in the char region of Bhola. At least 400 freshwater ponds in the district, including those used for fish farming, have been inundated due to water breaching the embankments of those areas.

Shrimp farmers of the coastal divisions in Bangladesh help the nation to earn $\$ 500$ million annually exporting shrimp and shrimp products to Europe and the Americas. Many of the fish farm- 
ers have lost their farms and the house went under the water. A rancher, Omar Faruq said, "My home has gone beneath the water. My shrimp farm is gone. I don't know how I am going to survive". The coastal range of Bangladesh is known for shrimp culture and finfish aquaculture, so the dependent households are going to lose their livelihood.

A shrimp exporter, Modhusadan Mondol said, "'the coronavirus had brought one of the biggest export industries of Bangladesh to a halt and hope to restart the shipments once the lockdown is lifted. But the cyclone Amphan washed away my shrimp farm and thousands of other farms. We lost everything. It destroyed our only means of survival".

"I sent my family members to a house on a comparatively higher land on Wednesday night. Then I came to my boat and brought it to a canal. But I failed to take the boat to a safe distance from the river as big boats occupied the canal. On Thursday morning, I came to see my boat, but could not find it. The boat was my only source of income. Now I have lost everything, even my dreams", Gias Uddin Khondoker (32), a resident of Dhal Char island near the Bay of Bengal in Bhola said.

The super cyclone Amphan has left the coastal areas of the Sundarbans devastated with sheer brutality. The vast areas of Koyra and Dacope in Khulna adjacent to the Sundarbans coast have once again been devastated even before their recovery from the catastrophic cyclones Sidr and Aila. Besides this, 176,000 hectares of croplands including standing Boro rice paddies, vegetables (beans, papaya, green chili, peanut, and banana), betel leaf, and mango have been affected by Amphan flooding. Sixty to seventy percent mangoes of Satkhira district have been damaged, taking the amount of land to 3,000 - 4,000 hectares more.

The concerned authority has directed its officials to take all possible measures to protect the producers, farmers, and cultivators of the fisheries and livestock sector during the disaster caused by cyclone Amphan. The Ministry of Disaster Management and Relief in Bangladesh approved a budget of BDT 2.5 - 3 billion to repair embankments damaged by Amphan along with the allocation of 3100 Metric Ton rice, BDT 5,000,000 cash, BDT 3,100,000 for purchasing baby food, BDT 2,800,000 for purchasing cattle feed, and 42000 packets dry food to 19 districts as projected to be affected at various intensity by cyclone Amphan.
Already the coronavirus has taken a toll on people in Bangladesh. Now the cyclone has made them paupers and worse than the coronavirus pandemic. Still we don't know how the government will come up with this situation.

\section{Assets from publication with us}

- Prompt Acknowledgement after receiving the article

- Thorough Double blinded peer review

- Rapid Publication

- Issue of Publication Certificate

- High visibility of your Published work

Website: www.actascientific.com/

Submit Article: www.actascientific.com/submission.php

Email us: editor@actascientific.com

Contact us: +919182824667 